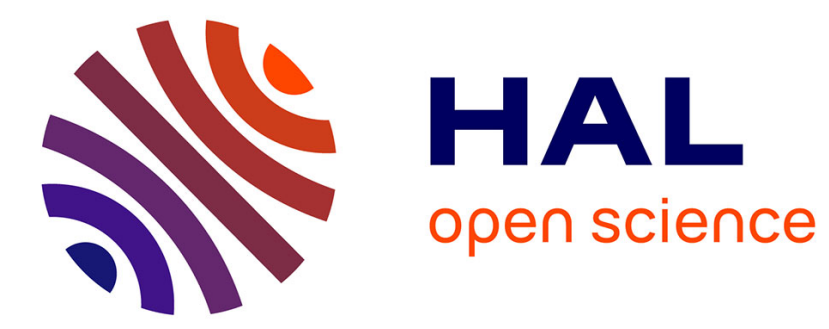

\title{
Fast and Accurate Determination of Olive Oil Acidity by Electrochemical Impedance Spectroscopy
}

Marco Grossi, Giuseppe Di Lecce, Tullia Gallina Toschi, Bruno Riccò

\section{To cite this version:}

Marco Grossi, Giuseppe Di Lecce, Tullia Gallina Toschi, Bruno Riccò. Fast and Accurate Determination of Olive Oil Acidity by Electrochemical Impedance Spectroscopy. IEEE Sensors Journal, 2014, 14 (9), pp.2947-2954. 10.1109/JSEN.2014.2321323 . hal-01276347

\section{HAL Id: hal-01276347 \\ https://hal.science/hal-01276347}

Submitted on 22 Mar 2016

HAL is a multi-disciplinary open access archive for the deposit and dissemination of scientific research documents, whether they are published or not. The documents may come from teaching and research institutions in France or abroad, or from public or private research centers.
L'archive ouverte pluridisciplinaire HAL, est destinée au dépôt et à la diffusion de documents scientifiques de niveau recherche, publiés ou non, émanant des établissements d'enseignement et de recherche français ou étrangers, des laboratoires publics ou privés. 


\title{
Fast and Accurate Determination of Olive Oil Acidity by Electrochemical Impedance Spectroscopy
}

\author{
Marco Grossi, Giuseppe Di Lecce, Tullia Gallina Toschi and Bruno Riccò, Fellow, IEEE
}

\begin{abstract}
Virgin olive oil is an important ingredient of the Mediterranean diet highly appreciated for its beneficial health effects due to the presence of mono-unsaturated fatty acids and antioxidant properties. The olive oil quality is defined by many parameters, among which acidity and peroxide index and according to international regulations, these two determinations are carried out in laboratory environment, by means of manual titration. This kind of method, however, cannot be used on oil production sites, where, instead, it would be desirable to know the main characteristics of the oil for proper product classification.

In this paper a new technique to measure olive oil acidity by electrical conductance is presented that allows for fast, costeffective and on-site measurements. Such a technique has been validated with a set of 55 olive oil samples. Two different oil emulsions have been used and compared for the measurements: based on a hydro-alcoholic solution $(60 \%$ ethanol $40 \%$ distilled water) and distilled water, respectively. The data show that the electrical conductance of the emulsion with hydro-alcoholic solution is a strong function of the olive oil acidity, that can be estimated with good accuracy $\left(\mathbf{R}^{2}=\right.$ 0.9308). The experiments with distilled water, instead, exhibit no significant correlation between oil acidity and emulsion conductance that, however, is found to provide information about peroxide index, polyphenols content and filtration technique.

Furthermore, using both types of emulsions to compensate for conductance variations other than free fatty acids the accuracy in acidity determination can be improved reaching $\mathbf{R}^{2}=\mathbf{0 . 9 7 8 6}$.
\end{abstract}

Index Terms - olive oil, acidity, quality, sensors, impedance, electrical conductance.

\section{INTRODUCTION}

$\mathrm{O}$ LIVE oil, produced from the olive fruit (Olea Europea L.) belonging to the family Oleaceae, represents an important ingredient of the diet and it is

Manuscript received February 3, 2014; accepted April 25, 2014.

Marco Grossi and Bruno Riccò are with Department of Electrical Energy and Information Engineering "Guglielmo Marconi" (DEI), University of Bologna, Bologna, Italy (e-mails: marco.grossi8@unibo.it, bruno.ricco@unibo.it).

Giuseppe Di Lecce is with Department of Food Science, Eurofins Chemical Control, Cuneo, Italy (e-mail: GiuseppeDiLecce@eurofins.com).

Tullia Gallina Toschi is with Department of Agricultural and Food Sciences - DISTAL, University of Bologna, Cesena, Italy (e-mail: tullia.gallinatoschi@unibo.it).

Copyright (c) 2013 IEEE. Personal use of this material is permitted. However, permission to use this material for any other purposes must be obtained by sending a request to pubs-permissions@ieee.org. highly appreciated for its beneficial effects on human health, mainly due to a high content of oleic acid and polyphenols [1]. A study on worldwide patterns of cancer mortality [2] has shown how mortality from breast and colorectal cancer is lower in countries with higher olive oil consumption. Moreover, olive oil properties appear also to reduce mortality from coronary heart diseases [3].

Currently, about $90 \%$ of the world olive oil production is from the Mediterranean basin with the European countries responsible for about $82 \%$ of the production [4]. Spain with over 320 million olive trees is the largest producer (37\% of the world production), followed by Italy (24\%) and Greece $(22 \%)$. Other emerging olive oil producers are California (USA), Australia, New Zealand and Chile [5].

Two of the most important parameters used to define olive oil quality are acidity and peroxide index. The former, defined as the amount of fatty acids no longer linked to their parent triglyceride molecules and expressed as grams of oleic acid in $100 \mathrm{~g}$ of oil, strongly depends on the quality and freshness of the olives used to produce the oil [6]. The peroxide index, instead, is a parameter used to quantify the oil primary oxidation and is defined as milliequivalent of active oxygen per kilogram of oil (meq $\mathrm{O}_{2} / \mathrm{kg}$ oil). Such an index is related to the ripeness of olives and the storage conditions of the oil after the production. During the storage period, both light and high temperatures negatively affect the peroxide value, making it to grow.

According to the measured values of acidity and peroxide index olive oil can be classified in different categories of product quality. The best is extra-virgin olive oil (EVOO), that must feature acidity $<0.8 \%$ and peroxide index $<20$. Virgin olive oil is characterized by acidity between $0.8 \%$ and $2 \%$ and peroxide index $<20$, while lampante olive oil features acidity higher than $2 \%$.

The European Commission regulation No. 2568/91, with subsequent amendments, defines manual titration, that must be carried out in a laboratory environment by trained personnel, as the reference methods to measure acidity and peroxide index in olive oil [7]. In many cases, such a technique requires sending oil samples to often far away labs and waiting days for responses, with significant costs and time wasting.

Therefore, a fast and cost-effective method to determine the main oil parameters on-site for proper product classification would be highly desirable, and innovative techniques have been proposed to this purpose, such as: 
optical Near-InfraRed (NIR) spectroscopy [8, 9], spectral nephelometry $[10,11]$, time domain reflectometry $[12,13]$ and $\mathrm{pH}$-metric determination [14]. These techniques are competitive with the reference methods in terms of measurement speed, but require expensive instrumentation and/or are characterized by low accuracy.

In this context, Electrochemical Impedance Spectroscopy (EIS) is a very promising technique that, in recent years, has been used for the characterization of different food products such as: apple bruise detection [15]; control of persimmons' ripening stage [16]; automatic classification [17] and control of the freezing process of ice-cream mixes [18]; detection of bacterial concentration in ice-cream [19, 20], raw milk [21], beer [22] and water [23]. The method consists in the application of a sinusoidal test voltage in a broad range of frequencies to the sample under test (SUT) and in the measurements of its electrical behavior, i.e. $|\mathrm{Z}|$ and $\operatorname{Arg}(Z)$, used to estimate the product parameters of interest.

The authors of this work have recently proposed to use EIS to measure olive oil acidity and shown encouraging preliminary results [24]. The proposed method is fast (response time in about 30 seconds) and usable for oil characterization in production environment, since: a) only non- dangerous and easily disposable ingredients are required; b) all solutions can be prepared in advance in disposable test-tubes, except, of course, for the addition of the oil to be characterized. In fact, such a technique can be used to realize sensors for fast, cost-effective and on-site characterization of olive oil at the production sites.

In such a technique the olive oil sample is mixed with a hydro-alcoholic solution to create an emulsion whose electrical conductance is then measured and it has been shown [24] to be strongly correlated to the oil acidity for samples featuring moderate-to-low oxidation (since secondary oxidation compounds directly affect electrical conductance). Moreover, since the sample electrical conductance depends also on oil storage conditions, the technique can also be used to evaluate product ageing and to discriminate EVOO samples from oils of lower quality.

This work describes in depth the technique to measure olive oil acidity by EIS. To this purpose, olive oil samples have been tested by creating an emulsion with two different aqueous solutions, one with a hydro-alcoholic solution (60\% ethanol $40 \%$ distilled water), the other with distilled water. A mathematical model to describe the relation between electrical conductance of the emulsion with hydroalcoholic solution and free acidity is presented and validated by means of measurements on a set of 55 olive oil samples.

The obtained results show that: a) the free acidity estimated using the hydro-alcoholic solution is accurate and adequate for most cases; b) taking into account the conductance of both the emulsions (with hydro-alcoholic and distilled water) a higher accuracy and a stronger correlation with data obtained with standard titration can be achieved.

\section{MATERIALS AND METHODS}

A set of 55 olive oil samples, taken both from local markets as well as Italian olive oil mills, have been investigated to study the correlation of the measured electrical parameters with the product free acidity and peroxide index.

For comparisons, the free acidity and peroxide index of all tested oils have been measured using the standard manual titration procedures defined by European Commission Regulation No. 2568/91 [7].

During the analysis period the oil samples have been stored in dark room at $18^{\circ} \mathrm{C}$ to avoid changes in the parameters of interest.

\section{A. Experimental Setup}

All measurements have been carried out using the experimental set-up shown in Fig. 1 (a). The oil emulsion with aqueous solution is hosted in a $50 \mathrm{ml}$ tube featuring a couple of stainless steel electrodes, with $6 \mathrm{~mm}$ diameter and $12 \mathrm{~mm}$ spacing between them, used for electrical characterization. Such a tube, hereafter referred to as "sensor", is stored in a Binder APT KB 53 thermal incubator at $20{ }^{\circ} \mathrm{C}$ to guarantee that all measurements are carried out at the same temperature. The electrical SUT characterization is carried out with the LCR meter Agilent E4980A by applying a sinusoidal test signal of amplitude $100 \mathrm{mV}$ and 55 logarithmically spaced frequencies in the range $20 \mathrm{~Hz}-2 \mathrm{MHz}$ (the electrical parameter $|\mathrm{Z}|$ and $\operatorname{Arg}(\mathrm{Z})$ are measured for each test frequency). A Laptop PC system is used to control the LCR meter by USB interface, display the results and data filing. All the software for instrumentation control has been realized with LabVIEW (National Instruments, USA).

Each oil sample has been tested using different solvents to create two type of emulsion:

- $15 \mathrm{ml}$ of hydro-alcoholic solution (60\% ethanol $40 \%$ distilled water) and $1 \mathrm{ml}$ oil,

$15 \mathrm{ml}$ of distilled water and $1 \mathrm{ml}$ oil.

The two solvents have been chosen because of their different polar properties: water is not miscible with olive oil but is capable of extracting from it some minor polar components (sugar, phenolic compounds, short chain free fatty acid) [25]; ethanol, on the other hand, shows a minor polarity due to the ethyl group $\mathrm{C}_{2} \mathrm{H}_{5}$, and reduces the extraction of polar compounds potentially interfering favoring the extraction of free fatty acids. After olive oil is added to the aqueous solution within the sensor, the obtained SUT is vigorously stirred for about 40 seconds to create the emulsion and its electrical characteristics are immediately measured with the LCR meter.

\section{B. Electrical Characterization of the Emulsion}

The tested samples have been electrically characterized for both emulsion types with the LCR meter. In Fig. 1 (b) the Bode plots $(|\mathrm{Z}|$ and $\operatorname{Arg}(\mathrm{Z})$ plotted vs. frequency) are shown for the oil emulsion with the hydro-alcoholic 
(a)

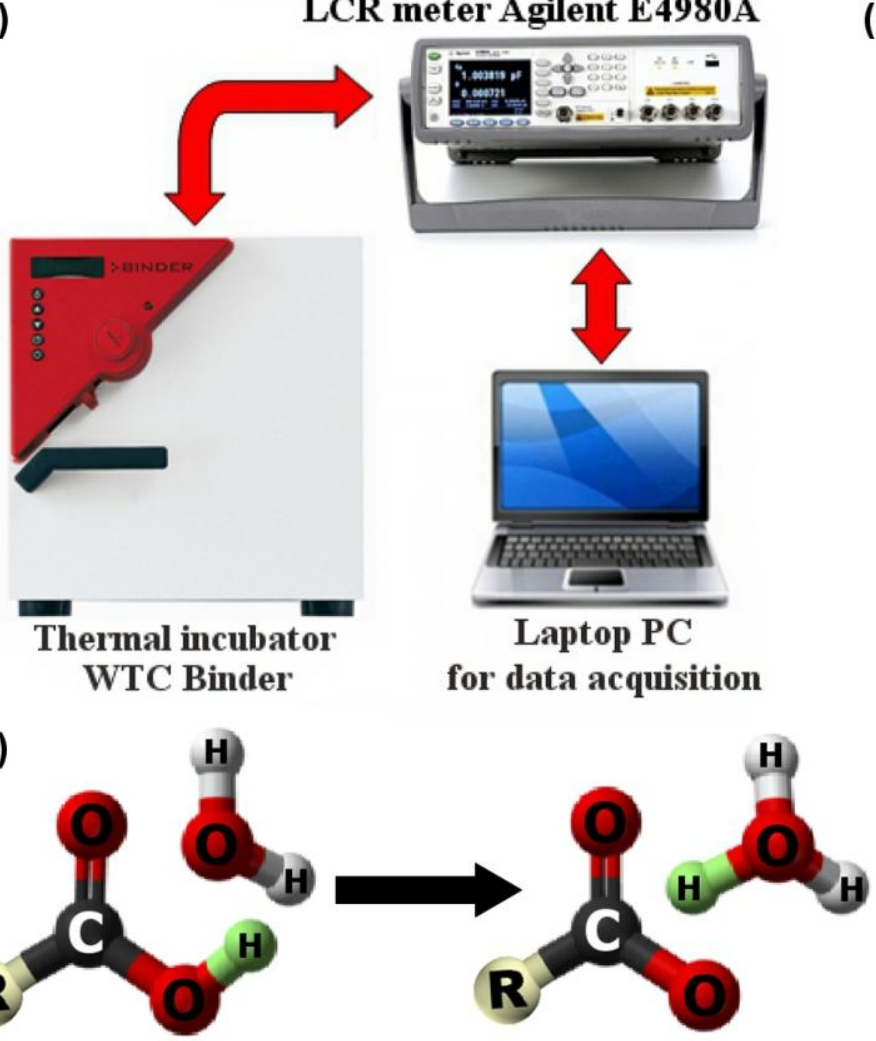

(b)
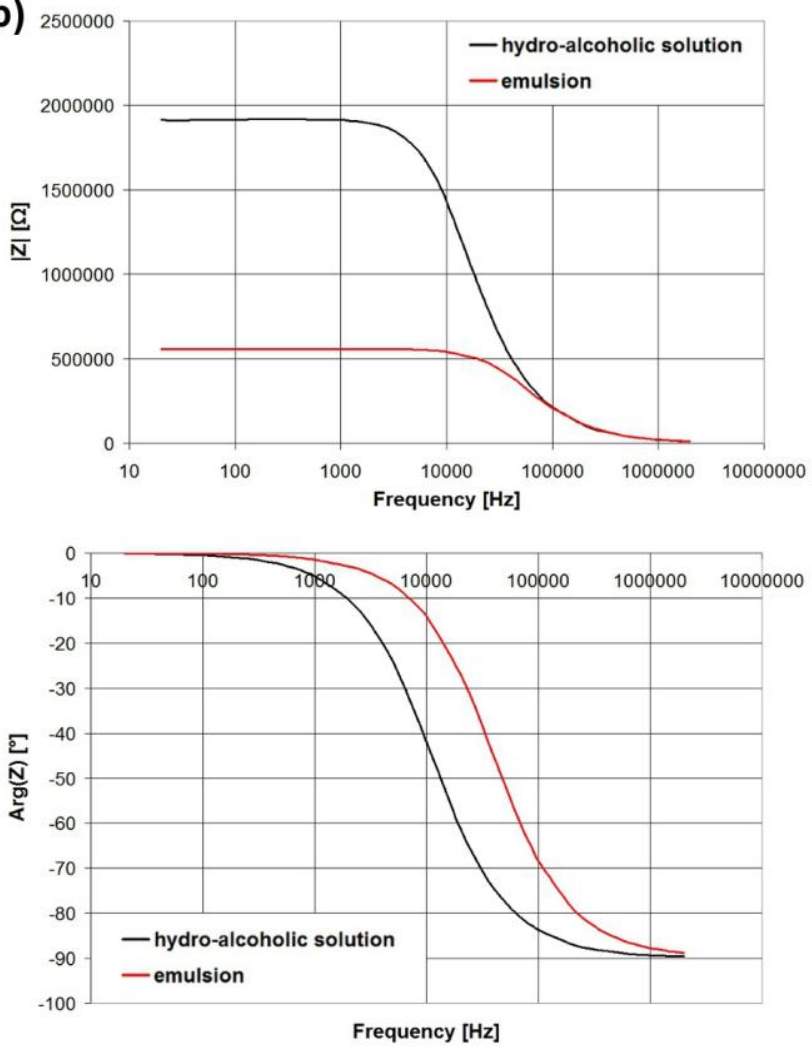

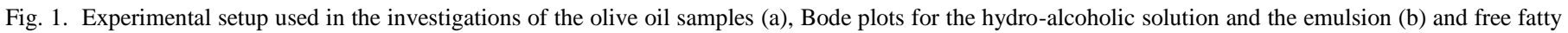
acid molecule and chemical reaction in presence of hydro-alcoholic solution (c).

solution. The curves feature a single-pole behavior in the investigated frequency range, that can be modeled with an equivalent circuit composed of a resistance $\left(R_{m}=1 / G_{m}\right)$ and a capacitance $C_{m}$ in parallel [24]. The curves obtained for the distilled water and the corresponding emulsion, not shown here, can also be modeled with such a circuit. The electrical parameters $G_{m}$ and $C_{m}$ have been extracted from the measured impedance spectra using the software Multiple Electrochemical Impedance Spectra Parametrization (MEISP) v3.0 by Kumho Chemical Laboratories. The capacitance $C_{m}$ is essentially due to the dielectric properties of the emulsion and has been found to be almost the same for all the tested samples. Since the dielectric properties of vegetable oils are known not to exhibit significant differences at frequencies lower than 100 $\mathrm{MHz}$, only the measured electrical conductance $\mathrm{G}_{\mathrm{m}}$ is considered hereafter.

\section{Model of the System Under Study}

As for the underlying chemistry, Fig. 1 (c) shows the dissociation reaction of the free fatty acid molecule (which belongs to carboxylic acid group), where $\mathrm{R}$ is the monovalent functional group $\mathrm{CH}_{3}\left(\mathrm{CH}_{2}\right)_{7} \mathrm{CH}=\mathrm{CH}\left(\mathrm{CH}_{2}\right)_{7}$. Long chain fatty acids, even if characterized by an high observed pKa [26], are classified as Brønsted-Lowry weak carboxylic acids due to their ability to donate a proton $\left(\mathrm{H}^{+}\right)$. The contribution to the electrical conductivity is essentially due to the $\mathrm{H}^{+}$ions since these are characterized by much higher mobility than the $\mathrm{RCOO}^{-}$group. Indicating with $\mathrm{n}$ the number of $\mathrm{H}^{+}$ions due to breaking of free fatty acid molecules $\mathrm{RCOOH}$ in $100 \mathrm{~g}$ of oil, and with $\mathrm{c}$ the olive oil acidity (number of $\mathrm{RCOOH}$ molecules in $100 \mathrm{~g}$ of oil), the electrical conductance $\mathrm{G}_{\mathrm{m}, \mathrm{RCOOH}}$ due to the ionization of fatty acids can be expressed as:

$$
G_{m, R \text { Соон }}=K_{F} \Lambda_{m} n=K_{F} \Lambda_{m} \alpha c
$$

where $\mathrm{K}_{\mathrm{F}}$ accounts for the electrodes geometry, $\Lambda_{\mathrm{m}}$ is the molar conductivity (electrical conductivity for 1 mole of electrolyte) and $\alpha$ is the degree of dissociation of the electrolyte. For weak electrolytes, as is the case for free fatty acids, $\alpha$, defined as the ratio between $\Lambda_{\mathrm{m}}$ and the molar conductivity at infinite dilution $\left(\Lambda_{\mathrm{m} 0}\right)$, is significantly lower than 1 and function of $c$. Denoting with $K_{c}$ the equilibrium constant of Ostwald's dilution law, it is:

$$
K_{c}=\frac{\alpha^{2} c}{1-\alpha}
$$

and, if $\alpha<<1$ it is:

$$
\alpha=\sqrt{\frac{K_{c}}{c}}
$$

Thus:

$$
G_{m, R C O O H}=K_{F} \sqrt{K_{c}} \Lambda_{m} \sqrt{c}
$$

The molar conductivity $\Lambda_{\mathrm{m}}$ also depends on the 

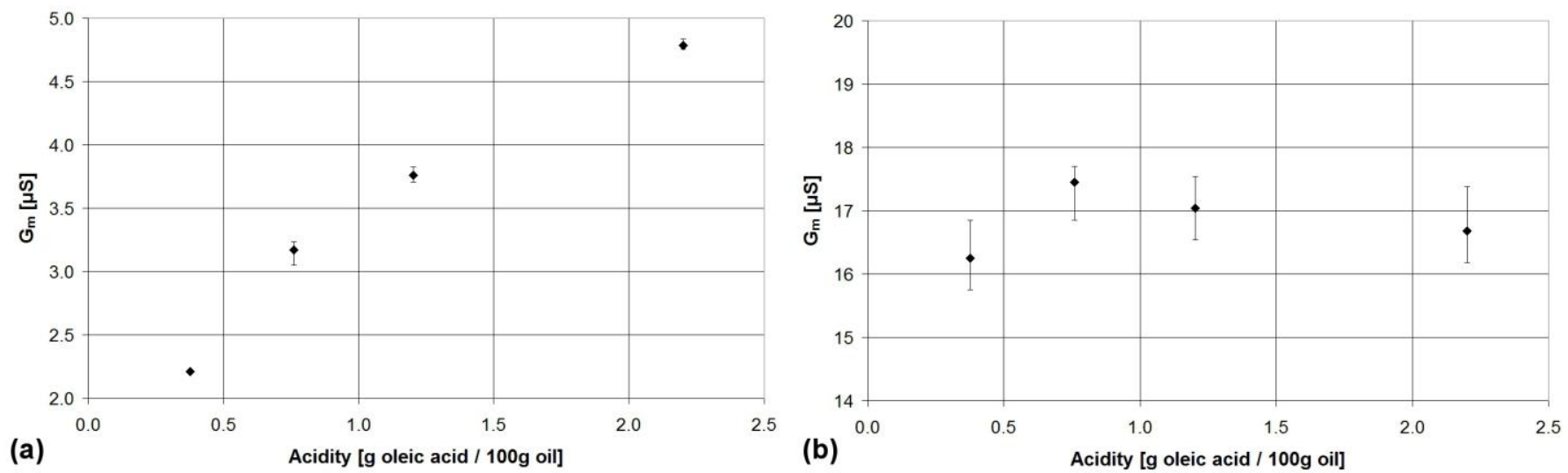

Fig. 2. Measured electrical conductance plotted vs. the sample acidity for the emulsion with hydro-alcoholic solution (a) and distilled water (b).

electrolyte concentration due to the variation of ions mobility with concentration (affecting inter-ion interaction). To model this effect, the Kohlrausch's law, strictly valid for strong electrolytes, can be used, at least as a first approximation, replacing the electrolyte concentration $\mathrm{c}$ with the concentration of dissociated electrolytes $\mathrm{n}$. Thus:

$$
\Lambda_{m}=\Lambda_{m 0}-K_{i} \sqrt{n}=\Lambda_{m 0}-K_{i} \sqrt[4]{K_{c}} \sqrt[4]{c}
$$

Indicating with $\Delta \mathrm{G}_{\mathrm{m} 0}$ the variation of the electrical conductance due to oil compounds other than free fatty acids, it is:

$$
G_{m}=\Delta G_{m 0}+G_{m, R C O O H}=k_{1}+k_{2} \sqrt{c}-k_{3} \sqrt[4]{c^{3}}
$$

Equation (6) can be used, as first approximation, to model the electrical conductance of the emulsion as function of oil acidity. A more detailed model should consider that $\Delta \mathrm{G}_{\mathrm{m} 0}$ differs from sample to sample. As discussed in the next Section, the measured electrical conductance of the emulsion with distilled water $\left(\mathrm{G}_{\mathrm{m}, \mathrm{mQ}}\right)$ is not affected by sample acidity, hence its value can be used to estimate $\Delta \mathrm{G}_{\mathrm{m} 0}$. Thus, Eq. 6 can be replaced by the more refined expression:

$$
G_{m}=k_{1 a} G_{m, m Q}+k_{1 b}+k_{2} \sqrt{c}-k_{3} \sqrt[4]{c^{3}}
$$

In this work, Equations (6) and (7) have been used to fit the measured data. All statistical analysis has been carried out with Microsoft EXCEL, while curve fitting has been made using the EXCEL add-on XLSTAT with non-linear regression. The estimated value of acidity has been determined by solving the non-linear equations (6) and (7) using the EXCEL function Goal Seek.

\section{RESULTS AND DISCUSSION}

First, the effects of oil acidity on the electrical conductance of both hydro-alcoholic and distilled water emulsions have been experimentally investigated and compared, finding that the former case is suitable to measure oil acidity.

Successively, the latter case has been considered to identify the contribution of the oil compounds to the electrical conductance of the emulsion, to study the possibility to use such an emulsion for further oil qualification.
Finally, the mathematical model developed in Section 2.3 has been used to estimate the acidity of 55 olive oil samples, taken from local markets as well as Italian oil mills.

\section{A. Effects of Oil Acidity on Emulsion Conductance}

Olive oil samples differing only for acidity value have been artificially created by adding known concentrations of oleic acid to a commercial virgin olive oil. Four different test samples have been created featuring acidity values of $0.35 \%, 0.75 \%, 1.25 \%$ and $2.25 \%$. All measurements have been carried out in triplicate and both mean value and standard deviation have been calculated. The measured electrical conductance $G_{m}$ is plotted vs. acidity in Fig. 2 for the emulsion created with the hydro-alcoholic solution (a) as well as with distilled water (b).

In the case of the hydro-alcoholic solution (Fig. 2 a), the emulsion conductance increases with acidity as expected from the model presented in Section 2.3. Fitting the experimental data with equation (6) results in the following

relation $G_{m}=-0.624+6.467 \sqrt{c}-2.321 \sqrt[4]{c^{3}} \quad$ with a coefficient of determination $\mathrm{R}^{2}=0.996$.

In the case of distilled water (Fig. 2 b), instead, the emulsion conductance does not exhibit evident correlation with the sample acidity. A Pearson correlation test has been carried out with a level of significance of 0.05 and the results (Pearson correlation coefficient $r$ of 0.094 and bilateral p-value of 0.772) confirm the absence of correlation between $G_{m}$ and sample acidity. The reason because free fatty acids affect the electrical conductivity of emulsions based on hydro-alcoholic components but not those using water is the polar characteristics described before. Smaller carboxylic acids (up to 5 carbon atoms) are soluble in water, while carboxylic acids linked to a longer alkyl chain are much less so due to their increasing hydrophobic nature (but are rather soluble in less polar solvents such as ethers and alcohols).

\section{B. Conductance of Emulsions with Distilled Water}

Since the electrical conductance of the emulsion between olive oil and distilled water does not depend on sample acidity, we have investigated if this kind of emulsion can be 

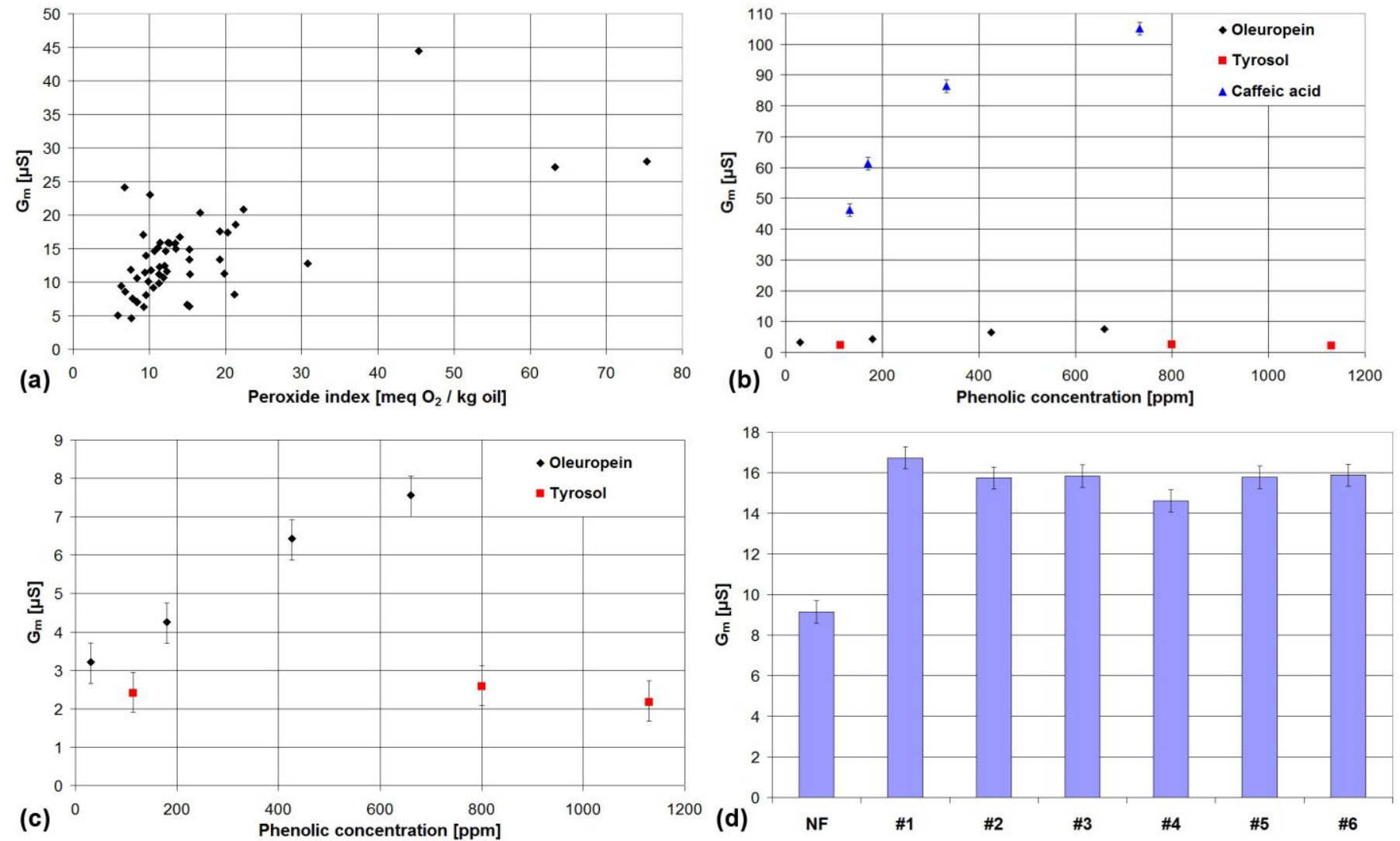

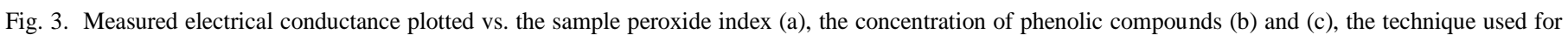
olive oil filtration (d). In all cases the electrical conductance has been measured for an emulsion between the oil sample and distilled water.

used to extract other oil parameters of interest, in particular the peroxide index and the phenolic content.

Fig. 3 (a) shows the measured value of $G_{m}$ vs. peroxide index for the 55 olive oil samples mentioned at the beginning of Section 2. A Pearson correlation test has been carried out with a level of significance equal to 0.05 . The calculated Pearson correlation coefficient $r$ is 0.648 (with a bilateral p-value $<0.0001$ ), clearly indicating the presence of correlation between $\mathrm{G}_{\mathrm{m}}$ and the peroxide index. Peroxides are formed from some fatty acids when the oil gets in contact with oxygen, during the milling process as well as during storage. Peroxides are unstable compounds that are further oxidized to produce volatile and nonvolatile compounds (such as aldehydes, ketones and hydrocarbons). The high $G_{m}$ value obtained for the oil samples with high peroxide index is probably affected by compounds produced by secondary oxidation. Since, the linear regression line correlating $\mathrm{G}_{\mathrm{m}}$ with peroxide index can be expressed as $G_{m}=0.346 \cdot P I+8.509$ with a coefficient of determination $\mathrm{R}^{2}=0.42$, only $42 \%$ of the data variability can be explained by the peroxide index.

To investigate if phenolic compounds can affect the emulsion conductance, standard reference compounds of two major phenolic compounds (oleuropein and tyrosol) and a minor compound (caffeic acid), usually present in very small amount in EVOO, have been dissolved in distilled water in different concentrations and the electrical conductance of the obtained sample has been measured. The results are presented in Fig. 3 (b) for the three compounds and in Fig. 3 (c) for only oleuropein and tyrosol. In the case of tyrosol no significant correlation has been found between $G_{m}$ and the different level concentrations (a Pearson correlation test with a significance of 0.05 has been carried out and the results, $r=$ -0.144 and $\mathrm{p}$-value $=0.711$ confirm the absence of correlation). Oleuropein concentration, instead, features a significant linear correlation with $G_{m}\left(R^{2}=0.986\right)$, while with caffeic acid $\mathrm{G}_{\mathrm{m}}$ variation depends on the concentration and it is about 10 times higher than in the case of oleuropein but the relation is nonlinear. In fact, the measured data vs. concentration have been found to exhibit a squared root type of relationship, indicating that caffeic acid behaves as a weak electrolyte in distilled water.

The variation of $G_{m}$ as function of filtered technique used to treated olive oil is presented in Fig. 3 (d). A non filtered olive oil (NF) has been filtered using six different techniques: \#1 precoat with cellulose fiber M09, dosing with cellulose fiber M09; \#2 precoat with cellulose fiber M09 and diatomaceous earth enoradal 3, dosing with cellulose fiber M09 and diatomaceous earth enoradal 3; \#3 precoat with cellulose fiber Arbocel BC200, dosing with diatomaceous earth Dicalite 6000 (coadjuvant 10\%); \#4 precoat with cellulose fiber Arbocel BC200, dosing with diatomaceous earth Dicalite 6000 (coadjuvant 15\%); \#5 precoat with diatomaceous earth enoradal 3, dosing with 

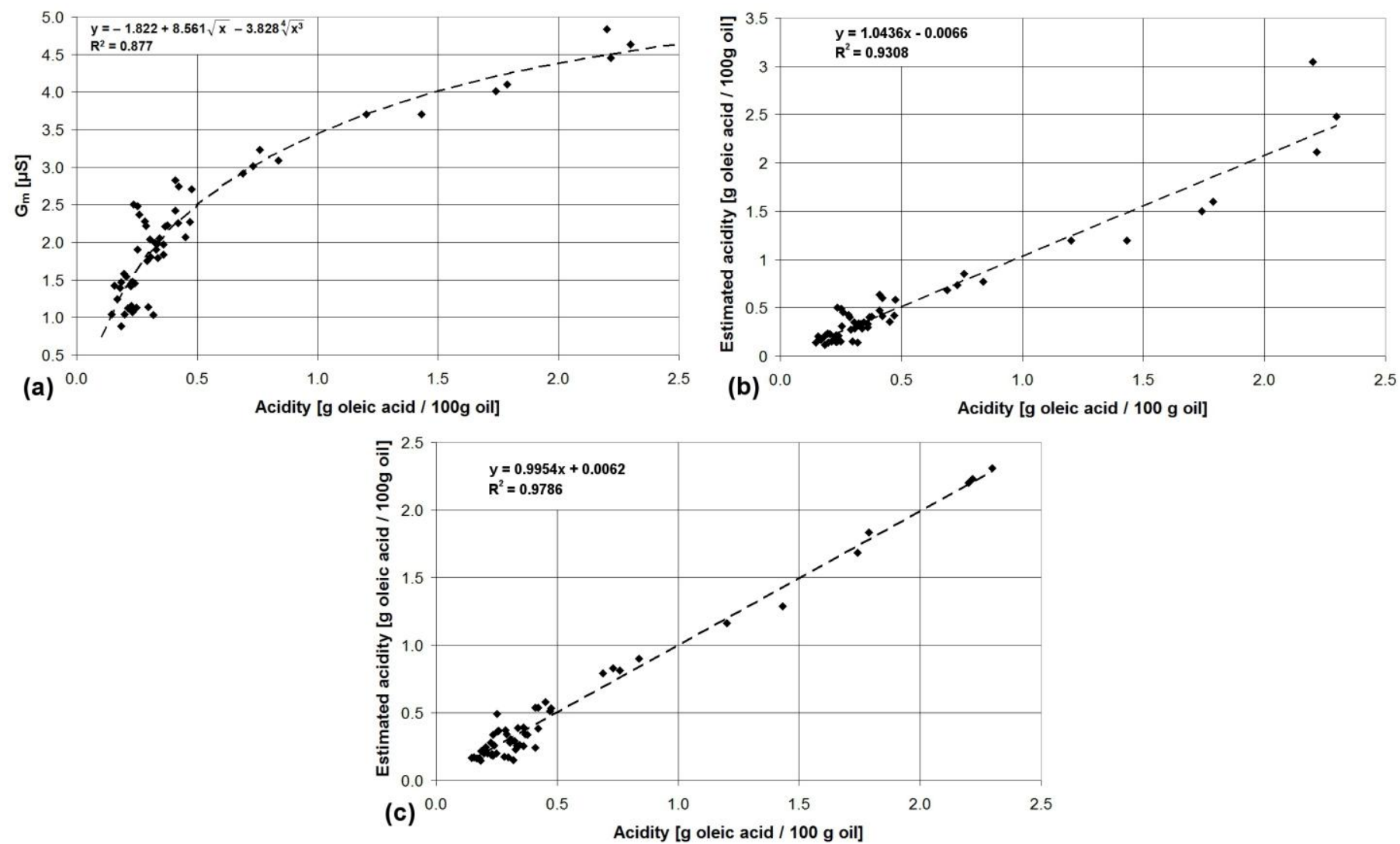

Fig. 4. Measured electrical conductance plotted vs. sample acidity in the case of emulsion between oil sample and hydro-alcoholic solution (a). Sample acidity estimated by the measured electrical conductance of emulsion with (b) hydro-alcoholic solution and (c) both hydro-alcoholic solution and distilled water plotted vs. sample acidity measured with the reference method.

diatomaceous earth onoranda 3; \#6 precoat with cellulose fiber M09, dosing with diatomaceous earth enoradal 3. The $\mathrm{G}_{\mathrm{m}}$ of emulsions created between each sample and distilled water has been measured (in all cases in triplicate). An ANOVA test (with a level of significance of 0.05) has also been performed to test significant differences in $G_{m}$ between the 7 samples.

The results indicate that three different groups (including samples whose $G_{m}$ value is not significantly different) can be identified: group A (\#1, \#2, \#3, \#5, \#6), group B (\#2, \#3, $\# 4$, \#5, \#6) and group $C(\mathrm{NF})$. The non-filtered sample features a $\mathrm{G}_{\mathrm{m}}$ (average value $9.132 \mu \mathrm{S}$ ) much lower than the others (ranging from $14.6 \mu \mathrm{S}$ to $16.731 \mu \mathrm{S}$ ), while samples $\# 2$, \#3, \#5, \#6 can be associated to both groups A and B. A significant difference in $G_{m}$ exists between sample \#1 and sample \#4.

\section{Acidity Measurement}

The set of 55 olive oil samples has also been tested to investigate the accuracy in acidity determination. Fig. 4 (a) shows the measured $G_{m}$ of the emulsion in hydro-alcoholic solution vs. the acidity and data fitted with equation (6): the resulting equation is $G_{m}=-1.822+8.561 \sqrt{c}-3.828 \sqrt[4]{c^{3}}$ and the coefficient of determination $\mathrm{R}^{2}=0.877$. By calculated non-linear equation, acidity has been estimated using the EXCEL function Goal Seek. Fig. 4 (b) shows the estimated acidity vs. acidity determined by means of titration: the linear regression equation $\mathrm{y}=1.0436 \mathrm{x}-$ 0.0066 and the high coefficient of determination $\left(\mathrm{R}^{2}=\right.$ 0.9308) show that the value of acidity determined by Electrochemical Impedance Spectroscopy (EIS) is sufficiently accurate.

Finally, measured $\mathrm{G}_{\mathrm{m}}$ values for both the emulsions using the hydro-alcoholic solution and distilled water have been used to best fit Equation (7). With the result $G_{m}=0.068 G_{m, m Q}-0.586+3.001 \sqrt{c}-0.092 \sqrt[4]{c^{3}}$

(coefficient of determination $\mathrm{R}^{2}=0.959$ ) the acidity value has been estimated using EXCEL function Goal Seek and the results are presented in Fig. 4 (c). As can be seen, this procedure increases the accuracy of the estimated acidity value (linear regression equation $\mathrm{y}=0.9954 \mathrm{x}+0.0062$ and $\mathrm{R}^{2}=0.9786$ ) due to the compensation of $\mathrm{G}_{\mathrm{m}}$ variations in hydro-alcoholic solution caused by other than free fatty acids with the value measured in the emulsion with distilled water.

\section{Towards a Low-Cost Embedded System}

The proposed technique can be easily implemented in the form of a portable embedded system realized with low-cost electronics for in-situ measurements directly within olive oil mills. Preliminary measurements have shown that the emulsion electrical conductance can be reliably estimated (with error lower than $0.5 \%$ ) from the real component of the emulsion admittance measured at a single frequency lower 
than $100 \mathrm{kHz}$. This allows the measurement to be implemented using an "ad hoc" designed electronic board, similar to the one presented in [23].

As for temperature, that of the sample can be set to the target value by means of an heating system, to be controlled by a thermoregulation electronic board, as the one discussed in [23].

The further implementation of wireless transmission would allow rapid collection of data through a sensor network for real-time, quick quality control.

Future work will be focused on the realization of such a system where the user would have only to inoculate a known quantity of the oil to be tested in a disposable container (in practice a lab tube modified as in [23]) prefilled with all other harmless and stable reagents required as discussed in Section 3 (in practice the hydro-alcoholic solution).

After inserting the tube in the thermo-regulated socket, the oil acidity could then be immediately read.

\section{CONCLUSIONS}

In this paper a technique, based on Electrochemical Impedance Spectroscopy has been presented that allows to accurately estimate olive oil acidity by measuring the electrical conductance of an emulsion between the oil and an hydro-alcoholic solution $(60 \%$ ethanol $40 \%$ distilled water). Furthermore, it has been shown that the measured electrical conductance of an emulsion with only distilled water is not sensitive to oil acidity, but depends on other oil characteristics, in particular the presence of oxidized compounds.

A mathematical model expressing the electrical conductance of the emulsion in hydro-alcoholic solution as a function of oil acidity has been presented and validated by means of a set of 55 olive oil samples.

The results show how an accurate determination $\left(\mathrm{R}^{2}=\right.$ 0.9308) of olive oil acidity is feasible by measuring the electrical conductance of the emulsion with hydro-alcoholic solution. If really necessary, such a value can be further refined taking into account also the conductance of the emulsion in distilled water $\left(\mathrm{R}^{2}=0.9786\right)$, because this allows to compensate for conductance variations not due to free fatty acids. Moreover, measured conductance values in distilled water provide a rough estimate of the sample peroxide index.

The experiments of this work have been carried out with lab instrumentation. However, the presented technique can be implemented in the form of a low-cost electronic embedded system. In particular, it is suitable for the realization of a mobile, stand-alone instrument to be used for on-site (immediate) product characterization, thus leading to significant reductions in costs and time compared with the current practice requiring samples travelling to and from distant labs.

\section{ACKNOWLEDGMENT}

This work has been financially supported by the CESAR Project, RIDIIT program, funded by the Ministry of Economic Development (Italy).

\section{REFERENCES}

[1] S. Tulipani, M. Martinez Huelamo, M. Rotches Ribalta, R. Estruch, E. Escribano Ferrer, C. Andres-Lacueva, M. Illan and R.M. LamuelaRaventòs, "Oil matrix effects on plasma exposure and urinary excretion of phenolic compounds from tomato sauces: evidence from a human pilot study", Food Chemistry, vol 130, pp. 581-590, 2012.

[2] F. Levi, F. Lucchini and C. La Vecchia, "Worldwide patterns of cancer mortality", European Journal of Cancer Prevention, vol. 3, pp. 109-144, 1994.

[3] R. Estruch, M.A. Martínez-González, D. Corella, J. Salas-Salvadó, V. Ruiz-Gutiérrez, M.F. Covas, E. Gómez-Gracia, M.C. LópezSabater, E. Vinyoles, F. Arós, M. Conde, C. Lahoz, J. Lapetra, G. Sáez and E. Ros, "Effects of a mediterranean-style diet on cardiovascular risk factors", Annals of Internal Medecine, vol. 145, pp. 1-11, 2006.

[4] F. Carbonari and T. Sarnari, "Il mercato internazionale e nazionale dell'olio di oliva", ISMEA, pp. 1-13, 2013.

[5] http://www.oliveoilquotation.com/

[6] http://www.agbiolab.com/

[7] EC 1991 Commission Regulation (EEC) $2568 / 91$ of July $11^{\text {th }} 1991$ on characteristics of olive oil and on the relevant methods of analysis. Official EC Journal, L248, 0001-0083.

[8] S. Armenta, S. Garrigues and M. de la Guardia, "Determination of edible oil parameters by near infrared spectrometry", Analytica Chimica Acta, vol. 596, pp. 330-337, 2007.

[9] D. Ozdemir and B. Ozturk, "Near infrared spectroscopic determination of olive oil adulteration with sunflower and corn oil", Journal of Food and Drug Analysis, vol. 15, pp. 40-47, 2007.

[10] A.G. Mignani, P.R. Smith, L. Ciaccheri, A. Cimato and G. Sani, "Spectral nephelometry for making extravirgin olive oil fingerprints", Sensors and Actuators B, vol. 90, pp. 157-162, 2003.

[11] A.G. Mignani, L. Ciaccheri, A. Cimato, C. Attilio and P.R. Smith, "Spectral nephelometry for the geographic classification of Italian extra virgin olive oils", Sensors and Actuators B, vol. 111-112, pp. 363-369, 2005.

[12] A. Cataldo, E. Piuzzi, G. Cannazza and E. De Benedetto, "Dielectric spectroscopy of liquids through a combined approach: evaluation of the metrological performance and feasibility study on vegetable oils", IEEE Sensors Journal, vol. 9, pp. 1226-1233, 2009.

[13] A. Cataldo, E. Piuzzi, G. Cannazza, E. De Benedetto and L. Tarricone, "Quality and anti-adulteration control of vegetable oils through microwave dielectric spectroscopy", Measurement, vol. 43, pp. 1031-1039, 2010.

[14] Ya.I. Tur'yan, O.Yu. Berezin, I. Kuselman and A. Shenhar, "pHmetric determination of acid values in vegetable oils without titration", Journal of the American Oil Chemists Society, vol. 73, pp. 295-301, 1996.

[15] P.J. Jackson and F.R. Harker, "Apple bruise detection by electrical impedance measurement", HortScience, vol. 35, pp. 104-107, 2000.

[16] F.R. Harker and S.H. Forbes, "Ripening and development of chilling injury in persimmon fruit: an electrical impedance study", New Zealand Journal of Crop and Horticultural Science, vol. 25, pp. 149157, 1997.

[17] M. Grossi, M. Lanzoni, R. Lazzarini and B. Riccò, "Automatic icecream characterization by impedance measurements for optimal machine setting", Measurement, vol. 45, pp. 1747-1754, 2012.

[18] M. Grossi, R. Lazzarini, M. Lanzoni and B. Riccò, "A novel technique to control ice cream freezing by electrical characteristics analysis", Journal of Food Engineering, vol. 106, pp. 347-354, 2011.

[19] M. Grossi, M. Lanzoni, A. Pompei, R. Lazzarini, D. Matteuzzi and B. Riccò, "Detection of microbial concentration in ice-cream using the impedance technique", Biosensors and Bioelectronics, vol. 23, pp. 1616-1623, 2008.

[20] M. Grossi, A. Pompei, M. Lanzoni, R. Lazzarini, D. Matteuzzi and B. Riccò, "Total bacterial count in soft-frozen dairy products by 
impedance biosensor system", IEEE Sensors Journal, vol. 9, pp. 1270-1276, 2009.

[21] M. Grossi, M. Lanzoni, A. Pompei, R. Lazzarini, D. Matteuzzi and B. Riccò, "A portable biosensor system for bacterial concentration measurements in cow's raw milk", Proceedings of the $4^{\text {th }}$ IEEE International Workshop on Advances in Sensors and Interfaces (IWASI), Savelletri di Fasano, Italy, pp. 132-137, 2011.

[22] A. Pompei, M. Grossi, M. Lanzoni, G. Perretti, R. Lazzarini, B. Riccò and D. Matteuzzi, "Feasibility of lactobacilli concentration detection in beer by automated impedance technique", $M B A A$ Technical Quarterly, vol. 49, pp. 11-18, 2012.

[23] M. Grossi, R. Lazzarini, M. Lanzoni, A. Pompei, D. Matteuzzi and B. Riccò, "A portable sensor with disposable electrodes for water bacterial quality assessment", IEEE Sensors Journal, vol. 13, pp. 1775-1782, 2013.

[24] M. Grossi, G. Di Lecce, T. Gallina Toschi and B. Riccò, "A novel electrochemical method for olive oil acidity determination", Proceedings of the IEEE International Workshop on Advances in Sensors and Interfaces (IWASI), Bari (BR), Italy, June 13-14, pp. 162-167, 2013.

[25] E. Boselli, G. Di Lecce, M. Minardi, D. Pacetti and N.G. Frega, "Mass spectrometry in the analysis of polar minor components in virgin olive oil", Rivista Italiana delle Sostanze Grasse, vol. 84, pp. 3-14, 2007.

[26] J.R. Kanicky and D.O. Shah, "Effect of degree, type, and position of the unsaturation on the pKa of long-chain fatty acids", Journal of Colloid and Interface Science, vol. 256, pp. 201-207, 2002.

Marco Grossi received the Laurea degree in electronic engineering from the University of Bologna, in 2000 and the Ph. D. degree in 2004.

$\mathrm{He}$ is currently a post-doctoral fellow at the Department of Electronics, University of Bologna. He is involved in projects of innovative sensors for bacterial detection in food products and the characterization of food samples by electrical impedance spectroscopy. He is author and co-author of about 20 publications, most of which on internationally indexed peerreviewed journals.

Giuseppe Di Lecce graduated in 2005 in Food Science and Technology, at the Faculty of Agriculture, University of Bologna and in 2009 he obtained a Ph.D. in Food and Health at the Polytechnic University of Marche. He has worked with the group Antioxidantes Naturales, University of Barcelona, acquiring knowledge with the main analytical techniques with high resolution, and as post-doctoral research at the Department of Food Science, University of Bologna. He is currently responsible for people management at the Department of Food Chemistry, Eurofins Chemical Control. He is author and co-author of more 20 publications.
Tullia Gallina Toschi got a full-honours degree in Pharmaceutical Chemistry in '90. In '92 she worked in Scotland (Hannah Research Institute) under the direction of Dr. W.W. Christie, where she developed a competence in the field of stereospecific analysis of triglycerides and chromatographic and FT-IR analysis of trans (E) fatty acids. She is a founding member and coordinator of the OLIVE OIL SENSORY PANEL, recognized by Italian Ministry of Agricolture, of the Department of Agricultural and Food Sciences (DISTAL). She is the UNIBO coordinator of the project UNIBO POR FESR 2007/2013 Action 3 and took part, as coordinator of her research group, in European projects (ECROPOLIS - Organic Sensory Information System, 7th FP Grant agreement n. 218477-2 ). She's teacher of Food Analysis and Applications of Unit Operations (LM Chemistry, Food Technology L), tutor of more than fifty Degree and National and International Doctorate thesis, referee of several international journals and evaluator for the Italian ANVUR (VQR 2004-10). She is co-author of more than one hundred publications, most of which internationally indexed (h-index: 19/Scopus), she is Operational Manager of the Agri-Food Center of Applied Research, coordinator of the research group of Instrumental and Sensory Analysis (http://www.distal.unibo.it/it/ricerca/ambiti-di-ricerca/scienze-e-

tecnologie-degli-alimenti) and of the Food Waste Innovation Centre and President of the UNIBO Equal Opportunity Committee. She is co-editor of the Italian Journal of Food Science.

Bruno Riccò (SM'91-F'03) in 1971 graduated in electrical engineering at the University of Bologna (Italy); in 1975 received a Ph.D. from the University of Cambridge (U.K.) where he worked at the Cavendish Laboratory; in 1980 became Full Professor of Electronics at the University of Padua (Italy) and in 1983 at the University of Bologna (Italy); in the period 1981 - 1986 he was Visiting Professor at the University of Stanford, at the IBM Thomas J. Watson Research Center (Yorktown Heights) and at the University of Washington; from 1986 to 1996 was European Editor of the IEEE Transaction on Electron Devices; in 1995 received the G. Marconi Award for research by the Italian Association of Electrical and Electronics Engineers (AEI); 1998 became President of the Italian Group of Electronics Engineers; in 1999 was appointed European representative for the International Electron Device Meeting (IEDM); in 1999 founded the first university spin-off in Italy; in 2002 he has been elected Chairman of the IEEE North Italy Section; in 2003 was nominated Fellow of the IEEE.

Member of the Wlfson College of Cambridge (UK). Centennial Chair at the Indian Institute of Science, (Bangalore, India). Prof. Riccò has worked in the field of microelectronics and is (co-) author of over 450 publications (h-index Google Scholar 38), more than half published on major international Journals, of 3 books and 15 international patents. 